\begin{tabular}{llll}
\hline Bentham open & The Open Pain Journal \\
\hline CrossMark & Content list available at: www.benthamopen.com/TOPAINJ/ & $\substack{\text { The } \\
\text { Open Pain } \\
\text { lournal }}$ \\
\hline
\end{tabular}

RESEARCH ARTICLE

\title{
Pain Dreams and Dream Emotions in Patients with Chronic Back Pain and Healthy Controls
}

\author{
Michael Schredl ${ }^{1, *}$, Aline Kälberer ${ }^{2}$, Kai Zacharowski ${ }^{2}$ and Michael Zimmermann ${ }^{2}$ \\ ${ }^{I}$ Central Institute of Mental Health, Medical Faculty Mannheim/Heidelberg University, Mannheim, Germany \\ ${ }^{2}$ Department of Anaesthesia, Intensive Care Medicine and Pain Therapy, University Hospital Frankfurt, Frankfurt, \\ Germany
}

Received: December 22, 2016

Revised: May 12, 2017

Accepted: May 25, 2017

\begin{abstract}
:
Background:

Although some theorists have suggested that pain sensations cannot be part of the dreaming world, research has shown that pain sensations occur in about $1 \%$ of the dreams in healthy persons and in about $30 \%$ of patients with acute, severe pain.
\end{abstract}

\section{Objective:}

The present study is the first to study pain dreams in patients with chronic pain.

\section{Method:}

A questionnaire was administered to 100 patients with chronic lower back pain and 270 controls.

\section{Results:}

The patients reported more pain dreams and more negatively toned dreams compared to healthy controls. In addition, patients reported more often that the dreamed pain persisted into waking state.

\section{Conclusion:}

In patients, pain dreams might be instigated by actual pain whereas for healthy persons pain dreams might be pain memories (selfexperienced pain and/or seeing persons in pain). Future research should clarify how pain is processed during sleep. As patients with chronic pain experience negatively toned dreams, it will be beneficial to ask chronic pain patients about their dreams and, if necessary, offer specific treatment options like imagery rehearsal treatment.

Keywords: Pain dreams, dream emotions, chronic back pain, Toned dreams, Pain sensation, imagery rehearsal treatment.

Dreaming has been conceptualized as a virtual reality model of the world [1] or, quite similar, as an organized and selective simulation of the perceptual world [2]. This implies that the dreamer's perceptual experiences while dreaming should be comparable to waking perception. Research has, indeed, found that all dreams include visual perception and about $50 \%$ to $70 \%$ auditory perceptions whereas other sensory modalities like tactile sensations, gustatory and olfactory perceptions are quite rare - only found in about $1 \%$ of dreams [3 - 5]. For pain perception in dreams, a long held view was that pain perception does not exist in dreams, cf. the saying "I had to pinch myself to prove I wasn't dreaming" [6]. From an evolutionary viewpoint, Symons [7] argued that it wouldn't make sense to produce pain hallucinations

\footnotetext{
* Address correspondence to this author at: Central Institute of Mental Health J5, 68159 Mannheim, Germany; Tel: +49-621-1703-1782; Fax: +49-621-1703-1785; E-mail: Michael.Schredl@zi-mannheim.de.
} 
(experiencing pain within in the dream) as a response to pain stimuli during sleep because the cause of acute pain might be a predator and, thus, should result in an awakening as this is a serious threat to survival and producing offspring. Several studies $[5,6,8]$ analyzing laboratory dreams of healthy participants (more than 300 dream reports) indeed found no direct reference to pain, only one ambiguous reference to pain and, thus, support the notion of "pain-free" dreams. However, a closer look in the literature and subsequent studies reviewed below showed a different picture.

The first pain dreams were reported by Weygandt [9], he dreamed he was carrying a young lady for a while, not without trouble and, after waking up, he experienced the same back pain that he had experienced in the dream. His example and toothache dreams reported by adolescents [10] support the idea that pain sensations present during sleep can affect dreams in a similar way like external stimuli applied during sleep [11]. Nielsen et al. [12] used blood pressure cuffs above the knee which were inflated during REM sleep to induce a diffuse pain sensation (dull throbbing, mild aching, pins and needles sensation). As expected [see 7], the sleeper often awakened during the stimulation but 42 trails have been successful (i.e., no awakening) and $31.0 \%$ of those dreams contained references to pain experiences compared to $4.8 \%$ unstimulated control dreams [12]. In most dreams, the pain sensation was exactly the pain experience that persisted into waking; only two dreams included pain sensations of other persons or in other locations [12]. A subsequent study [13], however, using blood pressure cuffs on both hands could not replicate this finding; only two pain sensations occurred in 251 REM dreams and those two were control dreams without stimulation. The authors explained this finding by a much lower pain intensity using this paradigm.

The pain sensations in the control conditions raised the question as to whether pain in dreams can occur without actual pain during sleep. Zadra et al. [14] analyzed 3045 home dream reports and found 18 dreams with explicitly mentioned pain experiences $(0.59 \%)$. In only one person did the pain dream correspond to an existing back pain problem in waking state. The prevalence rates of pain dreams in a student sample $(\mathrm{N}=1612$ dreams; [15]) and in a long dream series [N $=$ 6541 dreams; 16$]$ were comparable (1.12\% and $1.04 \%$, respectively). The detailed analysis of the 68 pain dreams of the series indicate that in only two cases did the pain persist into the waking state and $79.4 \%$ of the dreamed pain situations (including the cause of pain in these situations) had never been experienced by the dreamer in his waking life [16]. Interestingly, the percentage of pain dreams is higher if specific rating scales asking for pain sensations were provided after the dream was recorded: $7.06 \%$ of 623 dreams [17] and $15 \%$ of 162 dreams [18].

Till now, only one study [19] systematically investigated pain dreams in 28 patients with severe pain (burn injuries): about $30 \%$ of all the dreams included pain sensations (using specific scales eliciting pain). A retrospective questionnaire study [20] in patients with burn injuries yielded similar results.

To summarize, the research thus far has demonstrated that actual pain during sleep can be a stimulus incorporated into the dream scenario. Secondly, it seems plausible that pain dreams might also occur without a pain stimulus during sleep, i.e., the dream reflects a waking-life pain experience (pain memory) or even pain observed in others (in the media, etc.) since observed pain can activate the corresponding brain areas in congenitally pain-insensitive persons [21].

The present study investigated the prevalence of pain dreams and the emotional tone of dreams in patients with chronic pain compared to healthy controls. Due to the continuity hypothesis which states that dreams reflect waking life [22] and the possibility of pain during sleep can cause pain dreams, we expected that patients with chronic pain would report pain dreams more often; and more often that the pain would persist after waking up. In addition, it was expected that dream emotions in the patient group were more negative compared to controls, as the chronic pain disorder causes significant distress during the day.

\section{METHODS}

\section{Dream Questionnaire}

For eliciting dream frequency, a 7-point scale $(0=$ never, $1=$ less than once a month, $2=$ about once a month, $3=$ about 2 to 3 times a month, $4=$ about once a week, $5=$ several times a week, $6=$ almost every morning) was presented. The retest reliability of the scale is high $(\mathrm{r}=.85,8$ weeks interval; [23]). The overall emotional tone of dreams was measured on a five-point scale $(-2=$ Very negative, $-1=$ Somewhat negative, $0=$ Neutral, $+1=$ Somewhat positive, +2 $=$ Very positive).The retest reliability over a two week period was $r=.617$ [24].

The participants were asked if they ever had experienced bodily pain within a dream. And if so, they should record the most recent pain dream as completely as possible. If pain dreams were remembered, the participants should estimate the percentage of pain dreams with regard to all remembered dreams and whether the pain experienced in the dream 
was similar to pain experienced in the waking state. In addition, they were asked whether the pain experienced in the dream was still present after waking up.

\section{SF-12 HEALTH SURVEY}

The SF-12 Health survey [25] encompasses 12 items about general health, bodily pain, physical functioning, mental health, vitality, and social functioning. Using regression equations, all twelve items were included in computing the Physical Health Score and the Mental Health Score. Both variables were standardized using the American Norms (Mean: 50, Standard Deviation: 10).

\section{PROCEDURE AND PARTICIPANTS}

The study was approved by the local ethics committee of the University of Frankfurt. Overall, 100 patients (63 women, 37 men) who were treated for chronic lower back pain in the outpatient department of the Anesthesia Clinic, Intensive Care Medicine and Pain Therapy, University Hospital Frankfurt, were included in the study. The typical pathologies were degenerative processes of the spinal disks, malformation of the lumbar spine, or pain after disc surgery. Only patients with chronic pain (more than six months) were included. Patients with a history of a tumor disease were excluded. Similarly, patients with acute pain conditions in addition to their chronic pain were also excluded. The mean age of the sample was 57.2 years, the standard deviation 11.72 years (range: 20 to 82 years). All patients were on medication; with only few exceptions on some form of opioid.

The control sample consisted of 270 persons (176 women, 94 men). About half of the participants were psychology students, the other participants were recruited within the social network of the second author. The mean age of the control sample was $35.94 \pm 16.80$ yrs. (range: 16 to 83 yrs.). Persons with chronic pain were not included.

Statistical procedures were carried out with the SAS 9.4 software package for Windows. Ordinal regressions (cumulative logit analyses) were used for analyzing the effect of different predictors on dream variables. For the interval scales, percentage of pain dreams, parametric regression analyses have been computed. As age differed significantly between the patient group and the control group $(\mathrm{t}=-13.6, \mathrm{p}<.0001)$, age was included in the regression analyses testing group differences.

\section{RESULTS}

The distributions for the dream recall frequency scale for the patient sample and the control sample are depicted in Table 1. The ordinal regression analysis indicated that there was a significant group difference (standardized estimate: $.1551, \mathrm{chi}^{2}=6.8, \mathrm{p}=.0093$ ) with higher dream recall in the patient sample, a significant decline with age (standardized estimate: $\left.-.4006, \mathrm{chi}^{2}=41.4, \mathrm{p}<.0001\right)$, and a non-significant gender difference (standardized estimate: $.0373, \mathrm{chi}^{2}=$ $0.5, \mathrm{p}=.4620)$.

Table 1. Dream recall frequency of patients with chronic back pain and healthy controls.

\begin{tabular}{|c|c|c|}
\hline Category & $\begin{array}{l}\text { Patients } \\
(N=100)\end{array}$ & $\begin{array}{c}\text { Control Sample } \\
(N=270)\end{array}$ \\
\hline Almost every morning & $10.0 \%$ & $8.9 \%$ \\
\hline Several times a week & $30.0 \%$ & $23.3 \%$ \\
\hline About once a week & $17.0 \%$ & $23.3 \%$ \\
\hline About 2 to 3 times a month & $13.0 \%$ & $13.7 \%$ \\
\hline About once a month & $12.0 \%$ & $10.0 \%$ \\
\hline Less than once a month & $8.0 \%$ & $13.7 \%$ \\
\hline Never & $17.0 \%$ & $7.0 \%$ \\
\hline
\end{tabular}

Patients reported more negatively toned dreams compared to the healthy controls (standardized estimate: -.3824 , $\left.\mathrm{chi}^{2}=28.2, \mathrm{p}<.0001\right)$; age (standardized estimate: $\left..1397, \mathrm{chi}^{2}=2.2, \mathrm{p}=.1397\right)$ and gender (standardized estimate: $.0765 \mathrm{chi}^{2}=1.7, \mathrm{p}=.1889$ ) were not associated with the emotional tone of the dreams. If the two scores of the SF-12 were also introduced, the group factor was no longer significant whereas mental health and physical health were independently related to more positive dream emotions (see Table 2), i.e., the more negatively toned dream in the patient group might be explained by their considerably lower scores regarding physical and mental health (see Table 3). Emotional tone and dream recall frequency were negatively correlated in the patient sample $(\mathrm{r}=-.341, \mathrm{p}=.0011, \mathrm{~N}=$ 88 ) but not in the control sample $(\mathrm{r}=.004, \mathrm{p}=.9534, \mathrm{~N}=254)$. 
Table 2. Ordinal regression analysis for emotional tone of dreams $(\mathrm{N}=341)$.

\begin{tabular}{|l|c|c|}
\hline Variable & $\boldsymbol{\beta}$ & \multicolumn{1}{|c|}{$\boldsymbol{\chi}^{2}$} \\
\hline Group (1 = Patients, 0 = Controls) & .0119 & 0.0 \\
\hline Age & .1526 & .9040 \\
\hline Gender & -.0641 & .0523 \\
\hline Physical Health Score (SF-12) & .3988 & 1.2 \\
\hline Mental Health Score (SF-12) & .4119 & 13.4 \\
\hline
\end{tabular}

$\beta=$ Standardized estimates

Table 3. Dream variables and SF-12 scores of patients with chronic back pain and healthy controls.

\begin{tabular}{|l|c|c|}
\hline Category & $\begin{array}{c}\text { Patients } \\
(\mathbf{N}=\mathbf{1 0 0})\end{array}$ & $\begin{array}{c}\text { Control Sample } \\
(\mathbf{N}=\mathbf{2 7 0 )}\end{array}$ \\
\hline Dream recall frequency & $3.14 \pm 2.00$ & $3.38 \pm 1.76$ \\
\hline Emotional tone of dreams ${ }^{1}$ & $-0.32 \pm 1.00$ & $0.22 \pm 0.74$ \\
\hline Pain dreams & $16.0 \%$ & $8.5 \%$ \\
\hline Physical Health Score $^{2}$ & $28.03 \pm 6.95$ & $50.53 \pm 8.08$ \\
\hline Mental Health Score $^{2}$ & $40.09 \pm 11.87$ & $47.69 \pm 9.36$ \\
\hline
\end{tabular}

${ }^{1} \mathrm{~N}=88$ for patients, $\mathrm{N}=253$ for control sample, ${ }^{2} \mathrm{~N}=99$ for patients, $\mathrm{N}=267$ for control sample

Sixteen patients $(16 \%)$ and twenty-three controls $(9 \%)$ reported that they had experienced bodily pain in their dreams (see Table 2). This group difference is significant (standardized estimate: .3688, chi $^{2}=8.8, \mathrm{p}=.0030$ ); age (standardized estimate: $-.3154, \mathrm{chi}^{2}=4.6, \mathrm{p}=.0316$ ); gender (standardized estimate: $-.1025, \mathrm{chi}^{2}=1.2, \mathrm{p}=.2720$ ), and dream recall frequency (standardized estimate: $.2411, \mathrm{chi}^{2}=4.5, \mathrm{p}=.0331$ ). In addition to the group difference, older persons tended to report pain dreams less often, and persons with higher dream recall were more likely to report pain dreams. In the patient group, reporting pain dreams was negatively associated with physical health $(\mathrm{r}=-.191, \mathrm{p}=.0578$, $\mathrm{N}=99)$ and mental health $(\mathrm{r}=-.266, \mathrm{p}=.0078, \mathrm{~N}=99)$. In the control group, only mental health was related to pain dreams $(\mathrm{r}=-.128, \mathrm{p}=.0367, \mathrm{~N}=267)$ but not physical health $(\mathrm{r}=.038, \mathrm{p}=.5367, \mathrm{~N}=267)$.

Of the 16 patients who reported that they had pain dreams, four patients were not able to recall a specific pain dream. The remaining 14 pain dreams could be divided into four groups: realistic pain dreams like experiencing severe back pain $(\mathrm{N}=4)$, dreams of being chased $(\mathrm{N}=4)$ with one dream including dogs biting the dreamer in his back, dreams of falling $(\mathrm{N}=2)$ with one dream in which the dreamer fell off a cliff and banged against the rocks, and bizarre pain dreams $(\mathrm{N}=2)$, e.g., the left foot of the dreamer was lying in a fire. Twenty participants of the control group reported a most recent pain dream: Most of them $(\mathrm{N}=9)$ were realistic but unusual pain experiences, e.g., snake biting the finger, loss of teeth, stabs with a knife, five dreams included realistic pain experiences like stomach ache, bang one's foot at a wall, three dreams were falling dreams with painful landings, and three dreams are clearly related to actual pain causing the awakening, due to leg posture or a hand that went numb with excessive prickling and led to awakening; one of the dreams included a pet panther biting the dreamer in his hand which prickled after waking up.

If pain dreams were remembered, the percentage of pain dreams with regard to all remembered dreams was much higher in patients with chronic back pain compared to controls: $47.80 \pm 26.14 \%(\mathrm{~N}=15$ patients $) v s .17 .52 \pm 18.09 \%$ $(\mathrm{N}=23$ controls), group effect $(\mathrm{F}=5.1, \mathrm{p}=.0288)$, age effect $(\mathrm{F}=0.0, \mathrm{p}=.9813)$, and gender effect $(\mathrm{F}=0.4, \mathrm{p}=$ $.5486)$ using a linear regression analysis.

Table 4. Pain quality experienced in the dream by patients with chronic back pain and healthy controls.

\begin{tabular}{|c|c|c|}
\hline Category & $\begin{array}{l}\text { Patients } \\
(\mathrm{N}=16)\end{array}$ & $\begin{array}{c}\text { Control Sample } \\
\left(\mathrm{N}=21^{1}\right)\end{array}$ \\
\hline Similar to waking pain experiences & 8 & 12 \\
\hline Different from waking pain experiences & 3 & 8 \\
\hline Don't remember & 5 & 1 \\
\hline
\end{tabular}

${ }^{1} \mathrm{~N}=2$ missing values

The estimates regarding quality of pain experienced in the dream are shown in Table 4. Most pain experiences were rated as similar to waking life, the reason for stating a difference was most often a different location compared to waking pain. The two groups did not differ regarding their estimates regarding similarity and differences between 
dreamed pain and waking pain $\left(\mathrm{Chi}^{2}=0.5, \mathrm{p}=.4786\right)$. More patients reported that pain persisted after waking up compared to the control group $\left(\mathrm{Chi}^{2}=5.8, \mathrm{p}=.0156\right)$ (see Table 5).

Table 5. Pain persisting after waking up (patients with chronic back pain and healthy controls).

\begin{tabular}{|l|c|c|}
\hline Category & $\begin{array}{c}\text { Patients } \\
(\mathbf{N}=\mathbf{1 6})\end{array}$ & $\begin{array}{c}\text { Control Sample } \\
(\mathbf{N}=\mathbf{2 3})\end{array}$ \\
\hline Pain did not persist after waking up & 1 & 10 \\
\hline Pain persisted after waking up & 12 & 11 \\
\hline Don't remember & 3 & 2 \\
\hline
\end{tabular}

\section{DISCUSSION}

Overall, the findings showed that patients with chronic back pain reported pain dreams more often than controls thereby indicating that pain sensations are part of the virtual dream world. In patients, it seems likely that actual pain is the instigator of pain sensations in dreams (pain persisted upon awakening) but for controls it might be more often pain memories. Moreover, dream emotions were more negative in patients compared to controls, mainly due to their impaired mental and physical health.

First, it has to be noted that the patients' dream recall frequencies were higher than those of the control group. One explanation might be a selection bias, i.e., only patients with high dream recall would like to participate in a study about dreaming and pain. The data of Table 1, however, indicate a large variance in dream recall in the patient sample, i.e., also patients with low dream recall participated. Another plausible explanation might be that dream recall frequency is increased in these patients because negatively toned dreams, especially nightmares, are more easily remembered than neutral dreams [26]; supported by the negative correlation between dream emotions and dream recall frequency. Another possible factor that might have increased dream recall frequency are nocturnal awakenings due to pain; this variable was not elicited in the present study but previous research [27] showed that, for example, the heightened dream recall in insomnia patients compared to healthy controls was explained by their higher frequency of nocturnal awakenings.

In this first study of pain dreams in a clinical population of chronic pain patients, a relatively simple questionnaire was used to elicit the occurrence of pain dreams. In order to obtain information closer to the actual event (remembering a dream, persistence of dream pain into waking), it would be very interesting to use dream diaries in this patient group including measures of pain intensity during the day. Using more sophisticated methods, like REM awakenings in the sleep laboratory do not seem to be practical as pain dream frequency is relatively low. On the other hand, that would be the only approach to differentiate between thoughts during nocturnal periods of wakefulness and REM or NREM dreaming - although previous studies in patients with sleep disorders [28] indicate that most persons can differentiate between these two phenomena.

Even though pain dream frequency was higher in the patient sample compared to the control sample - and, thus, supporting the continuity hypothesis of dreaming [22] - it should be noted that the majority of chronic back pain patients did not report pain dreams. The simplest explanation is, of course, dream recall itself: we found a significant effect of dream recall frequency on reporting pain dreams. One feasible option would be to use dream diaries because it has been shown that keeping a dream diary can increase dream recall frequency, especially in low dream recallers [29].

Another factor that might play a role is novelty: we studied chronic patients experiencing pain for at least six months. In sleep apnea patients, for example, the severe physiological changes due to oxygen desaturations during sleep scarcely affect dream content [30]. In order to test this hypothesis, it would be interesting to carry out longitudinal studies - if possible as close to the onset of pain as possible. Despite the much higher percentage of pain dreams, Raymond et al. [19] also noted that even severe and acute pain (burn victims) does not affect dreaming in the majority of the patients and speculated that there might be a reduced processing of pain sensation during sleep, especially REM sleep. Some evidence for that hypothesis is also provided by the present data as some pain dreams included nightmarish themes like being chased or falling. If the dreamer hadn't awakened due to the dramatic dream emotions, she or he might have slept soundly through this REM period and would not have remembered the pain sensations in this dream. Since the study of Nielsen et al. [12] is the only one so far using experimental induction of pain during sleep, it would be very interesting to study the effect of different types of pain stimuli on dream content; being aware of the fact that those stimuli should be below the awakening threshold. These results then could be compared to stimulation studies using other sensory modalities like sound, touch, or smell [11]. 
For patients with chronic back pain, the most likely cause of their pain dreams is actual pain because a high number of patients stating that pain persisted after waking. On the other hand, a significant number of healthy persons stated no persistence of the dreamed pain into the waking state, i.e., these pain dreams might be a reflection of pain memories $[15,16]$. To elucidate this hypothesis, it would be very interesting to study persons with periodic pain, e.g., persons with migraine, and compare pain dream frequencies in pain-free intervals with pain dream frequencies during their attacks. Interestingly, the dreams before waking up with a migraine attack are characterized by more anger and aggressive interactions [31] compared to awakenings without migraine but pain dreams have never been studied in that population. It would also be very interesting to study the hypothesis that dreams can not only reflect pain experienced by the dreamer in his or her waking life but might also reflect situations in which the person has seen another person in pain in real-life or via media. A considerable number of healthy participants said that the pain was different from the pain experienced in waking life and Schredl [16] also reported that pain dreams could include pain sensations never experienced in the dreamer's waking-life. One experimental design could be showing participants' video clips of persons in pain and then recording subsequent dreams.

Patients with chronic back pain reported more negatively toned dreams compared to the control group. One might speculate whether this might be related to possible side effects of pain medication, However, the difference could be explained by lower mental health and lower physical health and, thus, render a simple pharmacological effects of opioids unlikely. Unfortunately, the sample without opioids was too small to conduct meaningful statistical comparisons. In addition, the findings are in line with the literature reporting a close correlation between negative dreams and psychopathology [32] and between negative dreams and physical well-being [33]. As physical health is also related to the most intensive form of negative dreaming, i.e., nightmares, it would be very interesting to study nightmare frequency in this patient group; especially in view of the fact that some reported pain dreams are nightmarish. From a clinical viewpoint, it would be relevant not only to measure nightmare frequency but also the presence of a nightmare disorder, i.e., nightmares which cause significant distress and impaired daytime functioning [34]. As nightmare frequency is related to physical health [35], one would expect increased prevalence rates in chronic pain patients and, thus, offering specialized treatment, e.g., imagery rehearsal therapy [36], might be beneficial for this patient group.

\section{CONCLUSION}

To summarize, patients with chronic back pain reported more pain dreams and more negatively toned dreams compared to healthy controls. As this is the first dream study in chronic pain, further research must elucidate pain processing during sleep, i.e., how pain stimuli during sleep affect dreams and whether pain memories (self-experienced pain and/or seeing persons in pain) also contribute to the occurrence of pain dreams. Since these patients experience negatively toned dreams, it will be beneficial to ask chronic pain patients about their dreams and, if necessary, offer treatment options.

\section{ETHICS APPROVAL AND CONSENT TO PARTICIPATE}

This study was approved by the local ethics committee of the University of Frankfurt.

\section{HUMAN AND ANIMAL RIGHTS}

No animals were used in this research. All research procedures followed were in accordance with the ethical standards of the committee responsible for human experimentation (institutional and national), and with the Helsinki Declaration of 1975 , as revised in 2008 .

(http://www.wma.net/en/20activities/10ethics/10helsinki/).

\section{CONSENT FOR PUBLICATION}

Not applicable.

\section{CONFLICT OF INTEREST}

The authors declare no conflict of interest, financial or otherwise.

\section{ACKNOWLEDGEMENTS}

Declared none. 


\section{REFERENCES}

[1] Hobson JA. REM sleep and dreaming: towards a theory of protoconsciousness. Nat Rev Neurosci 2009; $10(11)$ : 803-13. [PMID: 19794431]

[2] Revonsuo A. The reinterpretation of dreams: an evolutionary hypothesis of the function of dreaming. Behav Brain Sci 2000; $23(6)$ : 877-901. [http://dx.doi.org/10.1017/S0140525X00004015] [PMID: 11515147]

[3] Zadra AL, Nielsen TA, Donderi DC. Prevalence of auditory, olfactory, and gustatory experiences in home dreams. Percept Mot Skills 1998; 87(3 Pt 1): 819-26. [http://dx.doi.org/10.2466/pms.1998.87.3.819] [PMID: 9885043]

[4] Snyder F. The phenomenlogy of dreaming. In: Madow L, Snow LH, Eds. The psychodynamic implications of the physiological studies on dreams. Springfield: Charles C. Thomas 1970; pp. 124-51.

[5] McCarley RW, Hoffman E. REM sleep dreams and the activation-synthesis hypothesis. Am J Psychiatry 1981; 138(7): 904-12. [http://dx.doi.org/10.1176/ajp.138.7.904] [PMID: 7258349]

[6] Arkin AM, Sanders KI, Ellman SJ, Antrobus JS, Farber J, Nelson WT. The rarity of pain sensations in sleep mentation reports. Sleep Res 1975; 4: 179 .

[7] Symons D. The stuff that dreams aren't made of: why wake-state and dream-state sensory experiences differ. Cognition $1993 ; 47(3)$ : $181-217$. [http://dx.doi.org/10.1016/0010-0277(93)90049-2] [PMID: 8370242]

[8] McCarley RW, Hobson JA. The form of dreams and the biology of sleep. In: Wolman BB, Ed. Handbook of dreams. New York: Van Nostrand 1979; pp. 76-130.

[9] Weygandt W. Entstehung der Träume. Leipzig: Grübel \& Sommerlatte 1893.

[10] Amanat E. Contents of day and night dreams of emotionally disturbed adolescents. Child Psychiatry Hum Dev 1974; 4(3): 157-67. [http://dx.doi.org/10.1007/BF01436023] [PMID: 4827134]

[11] Schredl M, Atanasova D, Hörmann K, Maurer JT, Hummel T, Stuck BA. Information processing during sleep: the effect of olfactory stimuli on dream content and dream emotions. J Sleep Res 2009; 18(3): 285-90. [http://dx.doi.org/10.1111/j.1365-2869.2009.00737.x] [PMID: 19552703]

[12] Nielsen TA, McGregor DL, Zadra A, Ilnicki D, Ouellet L. Pain in dreams. Sleep 1993; 16(5): 490-8. [PMID: 7690981]

[13] Zadra AL, Nielsen TA, Lavigne GJ, Germain A. Pain in stimulated and unstimulated laboratory dreams. Sleep Res 1996; 25 : 220.

[14] Zadra AL, Nielsen TA, Germain A, Lavigne G, Donderi DC. The nature and prevalence of pain in dreams. Pain Res Manag 1998; 3: 155-61. [http://dx.doi.org/10.1155/1998/946171]

[15] Knoth IS, Schredl M. Physical pain, mental pain and malaise in dreams. Int J Dream Res 2011; 4: 17-23.

[16] Schredl M. Frequency and nature of pain in a long dream series. Sleep Hypn 2011; 13: 1-6.

[17] Meaidi A, Jennum P, Ptito M, Kupers R. The sensory construction of dreams and nightmare frequency in congenitally blind and late blind individuals Sleep Medicine 2014; 15(5): 586-95. [http://dx.doi.org/10.1016/j.sleep.2013.12.008]

[18] Levitan L, LaBerge S. The stuff of dreams. NightLight. Lucitity Institute Newsletter 1994; 6(1): 9-14.

[19] Raymond I, Nielsen TA, Lavigne G, Choinière M. Incorporation of pain in dreams of hospitalized burn victims. Sleep 2002; 25(7): 765-70. [http://dx.doi.org/10.1093/sleep/25.7.765] [PMID: 12405613]

[20] Boeve SA, Aaron LA, Martin-Herz SP, et al. Sleep disturbance after burn injury. J Burn Care Rehabil 2002; 23(1): 32-8. [http://dx.doi.org/10.1097/00004630-200201000-00007] [PMID: 11803310]

[21] Danziger N, Faillenot I, Peyron R. Can we share a pain we never felt? Neural correlates of empathy in patients with congenital insensitivity to pain. Neuron 2009; 61(2): 203-12. [http://dx.doi.org/10.1016/j.neuron.2008.11.023] [PMID: 19186163]

[22] Schredl M. Continuity between waking and dreaming: a proposal for a mathematical model. Sleep Hypn 2003 ; 5: 38-52.

[23] Schredl M. Reliability and stability of a dream recall frequency scale. Percept Mot Skills 2004; $98(3$ Pt 2): $1422-6$. [PMID: 15291233]

[24] Schredl M, Berres S, Klingauf A, Schellhaas S, Göritz AS. The Mannheim Dream questionnaire (MADRE): Retest reliability, age and gender effects. Int J Dream Res 2014; $7:$ 141-7.

[25] Bullinger M, Kirchberger I. Fragebogen zum Gesundheitszustand (SF-36, SF-12). Göttingen: Hogrefe 1998.

[26] Schredl M. Dream recall: models and empirical data. In: The new science of dreaming - Volume 2: Content, recall, and personality correlates. Westport: Praeger 2007.

[27] Schredl M, Schäfer G, Weber B, Heuser I. Dreaming and insomnia: dream recall and dream content of patients with insomnia. J Sleep Res 1998; 7(3): 191-8.

[http://dx.doi.org/10.1046/j.1365-2869.1998.00113.x] [PMID: 9785274] 
[28] Schredl M. Do sleep disorders affect the dreaming process? dream recall and dream content in patients with sleep disorders. Sleep Med Clin 2010; 5(2): 193-202.

[http://dx.doi.org/10.1016/j.jsmc.2010.01.008]

[29] Schredl M. Questionnaire and diaries as research instruments in dream research: methodological issues. Dreaming 2002; 12 : 17-26. [http://dx.doi.org/10.1023/A:1013890421674]

[30] Schredl M, Schmitt J. Dream recall frequency and nightmare frequency in patients with sleep disordered breathing. Somnologie (Berl) 2009; 13: $12-7$. [http://dx.doi.org/10.1007/s11818-008-0359-3]

[31] Heather-Greener GQ, Comstock D, Joyce R. An investigation of the manifest dream content associated with migraine headaches: a study of the dreams that precede nocturnal migraines. Psychother Psychosom 1996; 65(4): 216-21. [http://dx.doi.org/10.1159/000289078] [PMID: 8843503]

[32] Levin R, Nielsen TA. Disturbed dreaming, posttraumatic stress disorder, and affect distress: a review and neurocognitive model. Psychol Bull 2007; 133(3): 482-528. [http://dx.doi.org/10.1037/0033-2909.133.3.482] [PMID: 17469988]

[33] Bódizs R, Simor P, Csóka S, Berdi M, Kopp MS. Dreaming and health: A theoretical proposal and some epidemiological establishments. Eur J Ment Health 2008; 3: 35-62. [http://dx.doi.org/10.1556/EJMH.3.2008.1.3]

[34] The international classification of sleep disorders (ICSD-3). Darien, IL: AASM 2014

[35] Sandman N, Valli K, Kronholm E, Revonsuo A, Laatikainen T, Paunio T. Risk factors for frequent nightmares among the general Finnish adult population. J Sleep Res 2014; 23(Suppl. 1): 49.

[36] Krakow B, Zadra AL. Imagery rehearsal therapy: Principles and practice. Sleep Med Clin 2010; 5: $289-98$. [http://dx.doi.org/10.1016/j.jsmc.2010.01.004]

(C) 2017 Schredl et al.

This is an open access article distributed under the terms of the Creative Commons Attribution 4.0 International Public License (CC-BY 4.0), a copy of which is available at: (https://creativecommons.org/licenses/by/4.0/legalcode). This license permits unrestricted use, distribution, and reproduction in any medium, provided the original author and source are credited. 